\title{
The intracellular, functional chloroplasts in adult sea slugs (Elysia crispata) come from several algal species, and are also different from those in juvenile slugs.
}

\author{
N.E. Curtis*, S.E. Massey*, J.A. Schwartz*, T. K. Maugel** and S.K. Pierce * \\ * Department of Biology, University of South Florida, Tampa, FL 33620 \\ ** Department of Biology, University of Maryland, College Park, MD 20742
}

The sacoglossan sea slug, Elysia crispata, sequesters chloroplasts from its algal food source within specialized cells lining the digestive diverticulum. These stolen chloroplasts photosynthesize within the slug cell cytoplasm as long as four months--one of the longest kleptoplastic associations known [1]. While many other sacoglossan species feed on and sequester chloroplasts from only one species of algae, adult $E$. crispata sequester plastids from three different species of algae; Penicillus capitatus, Halimeda incrassata, and Halimeda monile [2].

We have now done feeding experiments testing the ability of newlymetamorphosed, juvenile E. crispata, raised from egg masses in the lab, to sequester chloroplasts from multiple algal species using a large range of potential algal food sources. Surprisingly, juvenile E. crispata fed on different algal species (Bryopsis plumosa and Derbesia tenuissima) from those utilized for sources of symbiotic plastids in the adults. Transmission electron microscopy (TEM) verified that the B. plumosa and $D$. tenuissima chloroplasts were sequestered intracellularly in the juvenile slugs.

In addition, juvenile E. crispata fed exclusively on $B$. plumosa could be grown to adult size, and, as adults, they would switch to feeding on Penicillus capitatus if presented with it. Since the fine structure of B. plumosa and P. capitatus chloroplasts are easily distinguishable, TEM indicated that both types of chloroplasts are sequestered simultaneously inside the same cell in animals fed on both species of algae (Fig. 1).

Finally, a newly discovered population of E. crispata which lives in an area where only B. plumosa is present showed the presence of B. plumosa chloroplasts sequestered in adult slug digestive cells using TEM analysis and using molecular markers. Adult slugs fed on B. plumosa in the lab maintained chloroplasts for approximately as long as the field-collected animals. These results indicate that $E$. crispata not only eats several species of algae, but also is capable of maintaining symbiotic plastids concurrently from those species for long periods.

\section{References}

[1] S.K. Pierce et al., Biol. Bull. 204 (2003) 237-240.

[2] Curtis et al., Integ. Comp. Biol. 43 (2003) 861.

[3] This research was supported by the National Science Foundation (NSF grant \# IBN 0315227). In addition the assistance of Betty Loraamm and Kathleen Hotchkiss is gratefully acknowledged. 


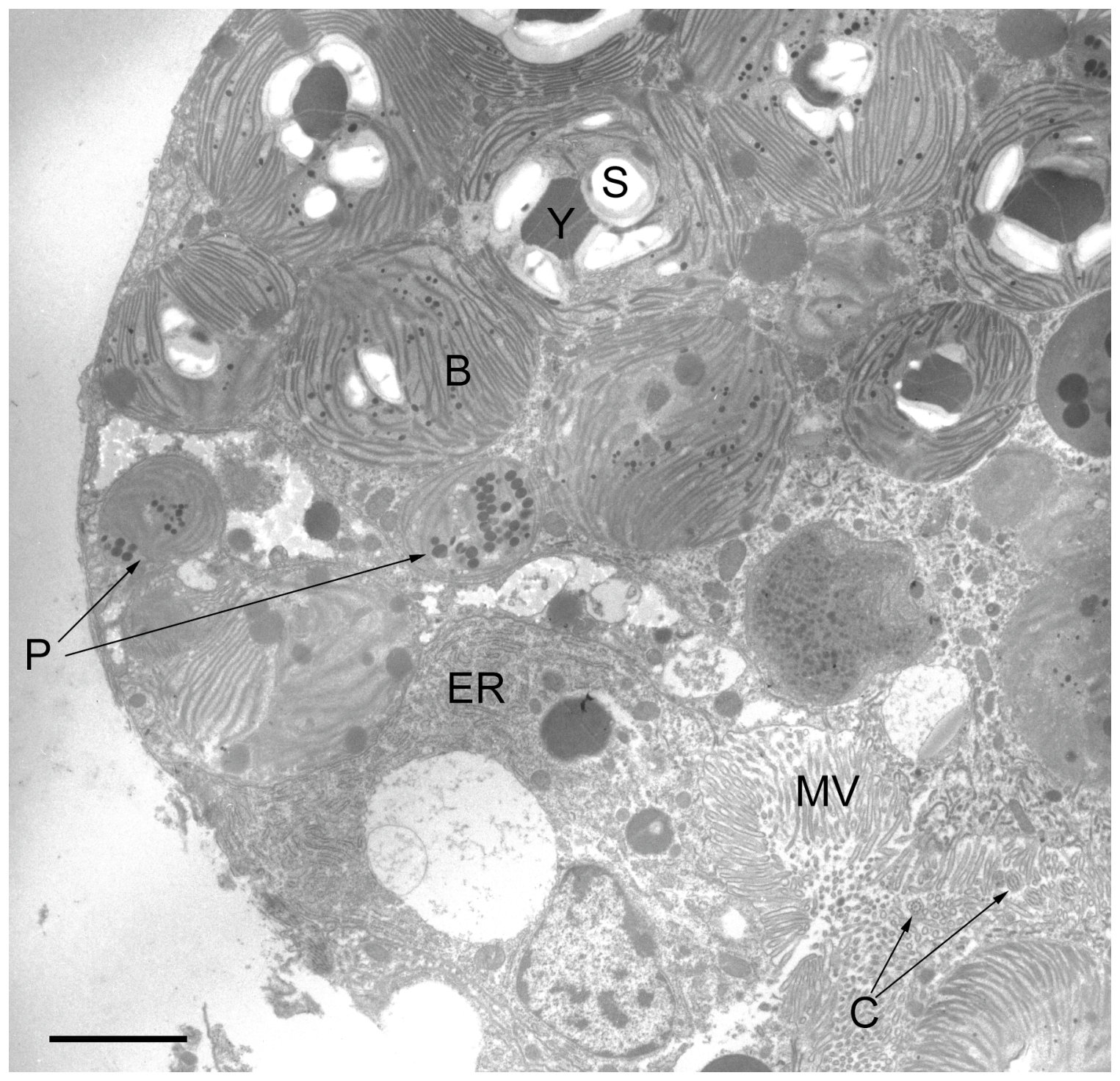

Figure 1. Section of a digestive tubule of an E. crispata which had been fed B. plumosa and then $P$. capitatus. Plastids from both species of algae are present in the same tubule cell. The $P$. capitatus plastids (arrows labeled $\mathrm{P}$ ) are much smaller than the B. plumosa plastids (B) and the latter contain starch granules (S) and a central pyrenoid body (Y). The lumen of the digestive tubule is full of microvilli (MV) and occasional cilia (arrows labeled C). Another type of tubule cell, containing mostly endoplasmic reticulum (ER) is present at the lower left. Scale bar $=3 \mu \mathrm{m}$ 